\title{
Comparison of sodium and calcium based sorbents for the dry treatment of flue gas from waste-to-energy plants
}

\author{
B. Zach ${ }^{1,2}$, M. Pohořelý ${ }^{1,2}$, M. Šyc ${ }^{1}$, K. Svoboda ${ }^{1} \&$ M. Punčochá ${ }^{1}$ \\ ${ }^{1}$ Environmental Process Engineering Laboratory, \\ Institute of Chemical Process Fundamentals of the CAS, Czech Republic \\ ${ }^{2}$ Department of Power Engineering, \\ University of Chemistry and Technology, Prague, Czech Republic
}

\begin{abstract}
This paper is focused on the properties of sodium and calcium based sorbents in relation to simultaneous dry flue gas treatment from $\mathrm{SO}_{2}, \mathrm{HCl}, \mathrm{NO}_{\mathrm{x}}$, solid particles and polychlorinated dibenzodioxins and dibenzofurans (PCDD/F). The most important differences between the two sorbent types are: the effect of temperature and moisture of flue gas on the sorption process, reactivity towards individual acid components in the flue gas (thermodynamic equilibrium and kinetics), and solubility of air pollution control residues. Also stoichiometric excess and mass of dosed sorbent is important for the comparison. The paper also presents new experimental unit for testing of complex flue gas treatment on catalytic filter elements. In this process, sorbent and reduction agent (for selective catalytic reduction of $\mathrm{NO}_{\mathrm{x}}$ ) are dosed in the flue gas. Solid particles (fly ash and sorbent) form a filter cake on the surface of the filter elements. The flue gas has to pass through the filter cake where the acid components react with the sorbent. Subsequently, relatively clean gas continues to the catalytic layer of the filter element. On the catalytic layer, $\mathrm{NO}_{\mathrm{x}}$ is reduced by reduction agent (e.g. $\left.\mathrm{NH}_{3}\right)$ and $\mathrm{PCDD} / \mathrm{Fs}$ are destroyed (oxidised) by residual oxygen in the flue gas. On this unit, simultaneous removal of $\mathrm{SO}_{2}, \mathrm{HCl}, \mathrm{NO}_{\mathrm{x}}$, solid particles and $\mathrm{PCDD} / \mathrm{F}$ can be studied.
\end{abstract}

Keywords: dry flue gas treatment, waste-to-energy, simultaneous, dry sorption. 


\section{Introduction}

Flue gas treatment is a very important part of every waste-to-energy (WtE) plant. Currently, dry flue gas treatment methods are very popular because they are not burdened by wastewater production. Frequently, there are attempts to simplify the process, lower the capital costs, operating costs, and the production of residues classified as hazardous waste.

This paper focuses on the comparison of sodium and calcium based sorbents in relation to treatment of flue gas from $\mathrm{WtE}$ plants at temperatures below $250^{\circ} \mathrm{C}$. This is a border temperature for technologies that combine dry sorption of acidic gases and catalytic oxidation of polychlorinated dibenzodioxins and dibenzofurans (PCDD/F) because, at this temperature, de-novo synthesis of $\mathrm{PCDD} / \mathrm{Fs}$ starts to take place. Another border temperature from the perspective of de-novo synthesis is $450^{\circ} \mathrm{C}$. Above this temperature is the production of PCDD/Fs by de-novo synthesis negligible. Therefore, technologies that combine dry sorption of acidic gases and catalytic oxidation of $\mathrm{PCDD} / \mathrm{Fs}$ have to evade temperatures between $250^{\circ} \mathrm{C}$ and $450^{\circ} \mathrm{C}$.

Sodium and calcium based sorbents are very often used for flue gas treatment and for treatment of other gaseous mixtures (e.g. producer gas). They are used for the removal of acidic gases such as $\mathrm{SO}_{2}, \mathrm{SO}_{3}, \mathrm{HCl}$, and $\mathrm{HF}$ (in some cases also $\left.\mathrm{CO}_{2}\right)$.

The most commonly used sodium based sorbent is sodium bicarbonate $\left(\mathrm{NaHCO}_{3}\right) . \mathrm{NaHCO}_{3}$ decomposes in flue gas into sodium carbonate $\left(\mathrm{Na}_{2} \mathrm{CO}_{3}\right)$, $\mathrm{H}_{2} \mathrm{O}$ and $\mathrm{CO}_{2}$. The decomposition is described by eqn (1). During the decomposition, the surface structure of sorbent particles is changed and the formed carbonate has very good properties for sorption of acidic gases. This reaction starts to take place (depending on the content of $\mathrm{H}_{2} \mathrm{O}$ and $\mathrm{CO}_{2}$ in the gas) already at $50{ }^{\circ} \mathrm{C}$; at $120^{\circ} \mathrm{C}$, the $\mathrm{NaHCO}_{3}$ decomposes quantitatively in seconds [1].

$$
\begin{gathered}
2 \mathrm{NaHCO}_{3} \rightarrow \mathrm{Na}_{2} \mathrm{CO}_{3}+\mathrm{H}_{2} \mathrm{O}+\mathrm{CO}_{2} \\
\mathrm{Na}_{2} \mathrm{CO}_{3}+\mathrm{SO}_{2} \rightarrow \mathrm{Na}_{2} \mathrm{SO}_{3}+\mathrm{CO}_{2}
\end{gathered}
$$

In flue gas, $\mathrm{Na}_{2} \mathrm{CO}_{3}$ reacts with the acidic gases in flue gas - e.g. according to eqn (2), where the reaction of $\mathrm{Na}_{2} \mathrm{CO}_{3}$ with $\mathrm{SO}_{x}$ and $\mathrm{HCl}$ is irreversible. It is, therefore, theoretically possible to use directly $\mathrm{Na}_{2} \mathrm{CO}_{3}$, assuming that the $\mathrm{Na}_{2} \mathrm{CO}_{3}$ would have sufficient surface. The mass of dosed $\mathrm{Na}_{2} \mathrm{CO}_{3}$ would be (at the same stoichiometric excess ratio) $37 \%$ lower than the mass of dosed $\mathrm{NaHCO}_{3} . \mathrm{Na}_{2} \mathrm{CO}_{3}$, however, has to be activated prior use. $\mathrm{Na}_{2} \mathrm{CO}_{3}$ is also hygroscopic and, therefore, has to be stored in dry conditions to avoid the sorption of water on the sorbent surface and consequently also surface modification.

$\mathrm{Na}_{2} \mathrm{CO}_{3}$ with sufficient reactivity can be also produced by decomposition of $\mathrm{Na}_{2} \mathrm{CO}_{3} \cdot \mathrm{H}_{2} \mathrm{O}$ but the process is very sensible to decomposition conditions (e.g. temperature and partial pressure of $\mathrm{H}_{2} \mathrm{O}$ in the gaseous phase) and therefore technologically complicated. And again, the produced sorbent adsorbs water so it has to be stored in dry conditions or immediately used. Successful attempts to produce $\mathrm{Na}_{2} \mathrm{CO}_{3}$ with good surface from $\mathrm{Na}_{2} \mathrm{CO}_{3} \cdot 10 \mathrm{H}_{2} \mathrm{O}$ are described in [2] but 
the process is too complicated for application in industrial scale. Moreover, $\mathrm{Na}_{2} \mathrm{CO}_{3} \cdot 10 \mathrm{H}_{2} \mathrm{O}$ decomposes at low temperatures - its thermal stability is $34^{\circ} \mathrm{C}$ but when the surrounding air is not fully saturated by water, the decomposition takes place even at lower temperatures. Storing of $\mathrm{Na}_{2} \mathrm{CO}_{3} \cdot 10 \mathrm{H}_{2} \mathrm{O}$ is, therefore, demanding in terms of temperature and humidity.

The most commonly used calcium based sorbents are $\mathrm{Ca}(\mathrm{OH})_{2}$ and $\mathrm{CaO} . \mathrm{CaO}$ reacts in flue gas very slowly because of its low surface. It, therefore, has to be slaked before use or the flue gas has to be conditioned (by addition of water) and the process operated at temperatures close to the dew point (usually $110-150^{\circ} \mathrm{C}$ ). During these conditions the $\mathrm{CaO}$ reacts with water vapour and forms $\mathrm{Ca}(\mathrm{OH})_{2}$ which then reacts with the acidic gases in flue gas.

\section{Comparison of sodium and calcium based sorbents}

Sodium and calcium based sorbents generally differ in several points. One of the important factors is the effect of temperature and humidity of flue gas on the sorbent reactivity.

The effect of humidity and temperature on the reactivity of sodium based sorbents is, in terms of dry flue gas treatment, insignificant [3]. According to Keener et al. [4], highest efficiency of $\mathrm{SO}_{2}$ removal can be achieved at temperatures around $180^{\circ} \mathrm{C}$ but is still satisfactory at $350^{\circ} \mathrm{C}$. However, higher temperature lead to oxidation of $\mathrm{Na}_{2} \mathrm{SO}_{3}$ to $\mathrm{Na}_{2} \mathrm{SO}_{4}$.

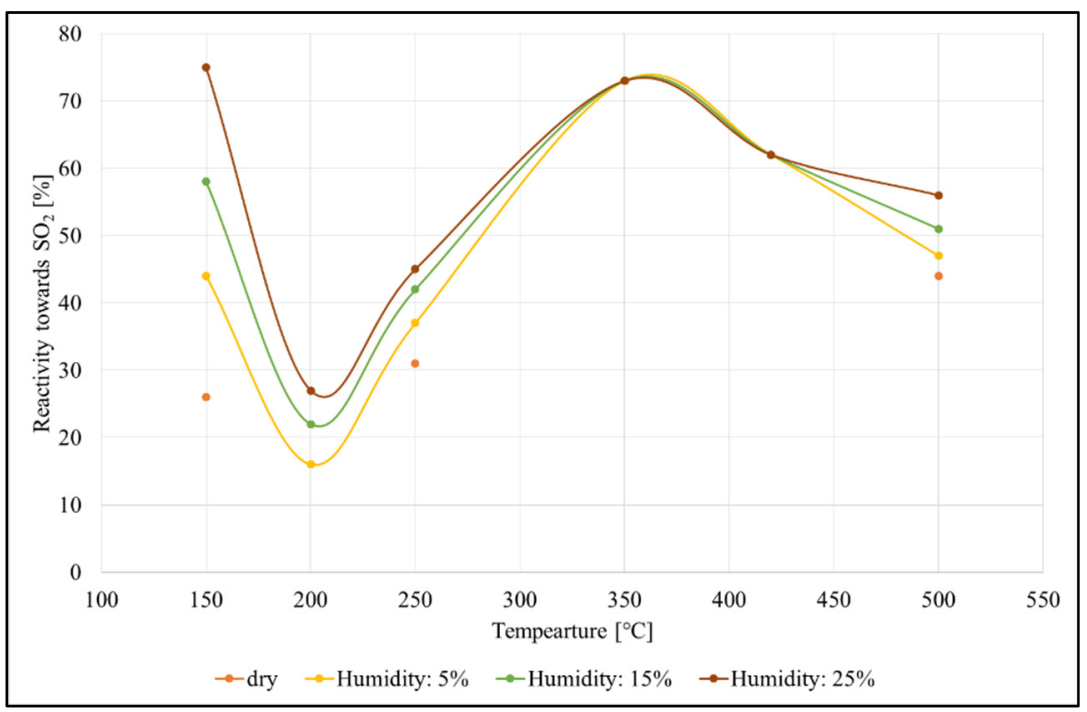

Figure 1: Dependence of reactivity of $\mathrm{Ca}(\mathrm{OH})_{2}$ towards $\mathrm{SO}_{2}$ on temperature and flue gas humidity.

Conversely, the efficiency of sorption on calcium based sorbents is very dependent on the temperature and the humidity of flue gas. For example, at $150^{\circ} \mathrm{C}$, 
the efficiency of $\mathrm{SO}_{2}$ removal by $\mathrm{Ca}(\mathrm{OH})_{2}$ is few times higher when the humidity is $25 \%$ than when the flue gas is dry. The reason is higher reactivity of $\mathrm{Ca}(\mathrm{OH})_{2}$ caused by condensation of water in the pores of sorbent particles. Therefore, the closer are the conditions to the dew point, the better is the sorption rate.

When the temperature is increased, the dependence of reactivity of $\mathrm{Ca}(\mathrm{OH})_{2}$ towards $\mathrm{SO}_{2}$ on the humidity of flue gas decreases and around $350^{\circ} \mathrm{C}$, the dependence is practically non-existent (see Figure 1).

When calcium sorbents are used, a minimum of reactivity towards $\mathrm{SO}_{2}$ usually occurs at around $200^{\circ} \mathrm{C}$ because this temperature is too high for condensation in the pores of the sorbent but the reaction kinetics (without the condensation) is still low at this temperature. Therefore, two maxima occur - under $150^{\circ} \mathrm{C}$ (in the vicinity of dew point) and over $300^{\circ} \mathrm{C}$, when the kinetics of the reaction is high because of the temperature, but the temperature isn't high enough for decomposition of $\mathrm{Ca}(\mathrm{OH})_{2}$. The reactivity of $\mathrm{Ca}(\mathrm{OH})_{2}$ towards $\mathrm{SO}_{2}$ is shown in Figure 1.

Sodium and calcium based sorbents differ also in their surface area. For example, the BET surface of calcium based sorbents ranges usually from 5 to $15 \mathrm{~m}^{2} / \mathrm{g}$ and some commercially produced sorbents based on $\mathrm{Ca}(\mathrm{OH})_{2}$ have surfaces over $40 \mathrm{~m}^{2} / \mathrm{g}$. Sodium based sorbents can have, on the other hand, significantly lower surfaces. The dependence of BET surface of $\mathrm{Na}_{2} \mathrm{CO}_{3}$ on the temperature of its formation by eqn (1) can be seen in Table 1 .

Table 1: The effect of formation temperature on the BET surface of $\mathrm{Na}_{2} \mathrm{CO}_{3}$. The formation is described by eqn (1).

\begin{tabular}{|c|c|}
\hline $\mathrm{t}\left[{ }^{\circ} \mathrm{C}\right]$ & BET $\left[\mathrm{m}^{2} / \mathrm{g}\right]$ \\
\hline 140 & 11.9 \\
\hline 300 & 4.5 \\
\hline 400 & 2 \\
\hline 500 & $<1$ \\
\hline
\end{tabular}

Calcium based sorbents have in comparison with $\mathrm{NaHCO}_{3}$ significantly lower reactivity towards $\mathrm{SO}_{2} \cdot \mathrm{NaHCO}_{3}$ is usually dosed at stoichiometric excess ratio 1.1-1.4 [3, 5]. For $\mathrm{Ca}(\mathrm{OH})_{2}$, the value ranges usually from 2.0 to 2.5 [3]. On the other hand, the molar weight of $\mathrm{Ca}(\mathrm{OH})_{2}$ is lower than of $\mathrm{NaHCO}_{3}$ and, according to eqn (3), theoretically only one mole of $\mathrm{Ca}(\mathrm{OH})_{2}$ is necessary for removal of one mole of $\mathrm{SO}_{2}$ (instead of 2 moles of $\mathrm{NaHCO}_{3}$ ). The consumption of sorbent by weight is, therefore, for $\mathrm{NaHCO}_{3}$ and $\mathrm{Ca}(\mathrm{OH})_{2}$ approximately the same.

$$
\mathrm{Ca}(\mathrm{OH})_{2}+\mathrm{SO}_{2} \rightarrow \mathrm{CaSO}_{3}+\mathrm{H}_{2} \mathrm{O}
$$

Calcium based sorbents have theoretically better properties for sorption of HF. The reactivity of $\mathrm{NaHCO}_{3}$ towards $\mathrm{HF}$ should nonetheless be sufficient for flue 
gas from WtE plant. The reactivity sequences eqns (4) and (5) show the selectivity of $\mathrm{NaHCO}_{3}$ and $\mathrm{Ca}(\mathrm{OH})_{2}$, respectively [3].

$$
\begin{array}{ll}
\text { Selectivity of } \mathrm{NaHCO}_{3}: & \mathrm{SO}_{3}>\mathrm{HCl}>\mathrm{SO}_{2}>\mathrm{HF}>\mathrm{CO}_{2} \\
\text { Selectivity of } \mathrm{Ca}(\mathrm{OH})_{2}: & \mathrm{SO}_{3}>\mathrm{HF}>\mathrm{HCl}>>\mathrm{SO}_{2}>\mathrm{CO}_{2}
\end{array}
$$

$\mathrm{NaHCO}_{3}$ is more suitable for sorption of $\mathrm{HCl}$ in terms of both kinetics and thermodynamic equilibrium. Calcium based sorbents $\left(\mathrm{CaCO}_{3}\right.$ not included $)$ reach the equilibrium at concentration of $\mathrm{HCl}$ that is orders of magnitude lower (than emission limits). The thermodynamic equilibrium of the reaction is, therefore, quite sufficient but the kinetics of the reaction is slow and the possibility to fulfil the emission limits depends on reaction conditions such as temperature, relative humidity, and reaction time.

The water insolubility of air pollution control residues represents another important advantage of calcium based sorbents. Both calcium sulfate and calcium sulfite are, contrary to sodium sulfate (sulfite), almost insoluble in water. The same goes for carbonates and hydroxides. Calcium based sorbents provide, therefore, from this point of view, a great advantage because the solubility of air pollution control residues significantly complicates and reduces the possibilities of its disposal. Apart from relatively expensive methods for treatment/disposal of watersoluble air pollution control residues, landfilling in old salt mines seems to be the only option. This way of disposal is usually (e.g. also in Germany) classified as utilisation. Another important factor is price, which favours calcium based sorbents but can significantly differ from country to country.

\section{Technologies that enable the removal of more pollutants in one step}

Recently, the efforts to simplify the technologies for flue gas treatment intensely grow. The simplification process consists mainly of development of technologies that enable removal of more than one pollutant in one step. The goal is to decrease the number of technological parts and, therefore, also capital costs, operating costs, the demand on staff, etc.

Simultaneous removal of more pollutants can be achieved by means of both dry (semidry) and wet methods. Wet methods can, for example, remove very small particles, acidic compounds and mercury (in form of $\mathrm{Hg}^{2+}$ compounds) by solution of alkali salts. Apart from the removal of mercury and other heavy metals (such as As and $\mathrm{Pb}$ ), wet technologies are also very good in terms of effective utilisation of reaction agent and covering of peaks of pollutant concentrations in flue gas. The main disadvantage of wet methods is the production of wastewater, which is expensive to process.

Dry methods can enable simultaneous catalytic removal of $\mathrm{NO}_{\mathrm{x}}$ and $\mathrm{PCDD} / \mathrm{F}$ because both processes can be catalysed by the same catalyst (e.g. based on $\mathrm{V}_{2} \mathrm{O}_{5}$ and $\mathrm{WO}_{3}$ ). Another possibility is simultaneous removal of $\mathrm{PCDD} / \mathrm{Fs}$ and particulate matter (PM), which can be realised by means of filter elements with a catalytic layer. Equally, simultaneous removal of $\mathrm{NO}_{\mathrm{x}}$ and $\mathrm{PM}$ is possible. 
Moreover, a sorbent (e.g. $\mathrm{NaHCO}_{3}$ or $\mathrm{Ca}(\mathrm{OH})_{2}$ ) for the removal of acidic compounds can be dosed before the filters. This way it is possible to remove PM, acidic compounds, $\mathrm{NO}_{\mathrm{x}}$, and $\mathrm{PCDD} / \mathrm{Fs}$. However, the optimal conditions for single processes differ. It is, therefore, necessary to look for suitable compromise in operation conditions.

In connection to dry technologies that enable the removal of more pollutants, the work of Choi et al. [6] is worth mentioning. Choi et al. tested simultaneous removal of $\mathrm{PM}$, acidic compounds and $\mathrm{NO}_{\mathrm{x}}$ on catalytic filter elements $\left(\mathrm{CuO} / \mathrm{Al}_{2} \mathrm{O}_{3}, \mathrm{~V}_{2} \mathrm{O}_{5} / \mathrm{TiO}_{2}\right.$ or $\left.\mathrm{V}_{2} \mathrm{O}_{5} / \mathrm{TiO}_{2} / \mathrm{SiO}_{2}-\mathrm{Al}_{2} \mathrm{O}_{3}\right)$. Their results suggest that the simultaneous removal of $\mathrm{PM}$, acidic compounds and $\mathrm{NO}_{\mathrm{x}}$, can be applicable in praxis. They also mention the possibility to use the catalyst for the removal of volatile organic compounds (VOC) and PCDD/Fs. However, they conducted the experiments at $300-350^{\circ} \mathrm{C}$, which are not temperatures suitable for the removal of $\mathrm{PCDD} / \mathrm{Fs}$ because of the de-novo synthesis of PCDD/Fs.

Our research is focused on the possibility to remove particulate matter, acidic compounds, $\mathrm{NO}_{\mathrm{x}}$, and $\mathrm{PCDD} / \mathrm{Fs}$ in one step by means of catalytic candle filter elements. This technology could help to simplify the flue gas treatment technology and, in small scale, lower the operating and capital costs and can be, therefore, suitable for small WtE plants.

One of the problematic aspects of this technology is the fact that optimal operation temperature differs for individual processes. However, all the processes take place in the baghouse and the operation temperature, therefore, has to be the same for all of them. The optimal temperature for selective catalytic reduction of $\mathrm{NO}_{\mathrm{x}}$ (SCR) ranges usually from 190 to $350^{\circ} \mathrm{C}$ depending on the flue gas composition, catalyst type and other process conditions. As was already mentioned, at temperatures between 250 and $450^{\circ} \mathrm{C}$, de-novo synthesis of $\mathrm{PCDD} / \mathrm{Fs}$ takes place [7] and the conditions in flue gas are favourable for this kind of synthesis. The process temperature, therefore, has to be lower than approximately $250^{\circ} \mathrm{C}$ but, at the same time, the temperature should be as high as possible because of the efficiency of SCR and minimisation of depositions of ammonia salts on the catalyst.

As was mentioned, the compromise temperature can cause lower efficiency of SCR. Two-stage removal of $\mathrm{NO}_{\mathrm{x}}$ is, therefore, planned for this technology. The first stage is represented by selective non-catalytic reduction of $\mathrm{NO}_{\mathrm{x}}$ (SNCR), which takes place directly in the incineration chamber and requires almost no additional equipment. The second stage is SCR. This process takes place in the baghouse and can be a very important factor in the case of change of emission limits because it can reach significantly higher efficiencies than SNCR.

The temperature of the process naturally affects also the choice of sorbent. As was already mentioned, calcium based sorbents show minimal reactivity at temperature around $200^{\circ} \mathrm{C}$. Therefore, if the operation temperature in the baghouse is $220^{\circ} \mathrm{C}$ (as in our case), sodium based sorbents (e.g. $\mathrm{NaHCO}_{3}$ ) are substantially more suitable. 


\section{Experimental apparatus}

For the purpose of testing of flue gas treatment by means of catalytic candle filter elements, an apparatus was constructed. The experimental apparatus is shown in Figure 2.

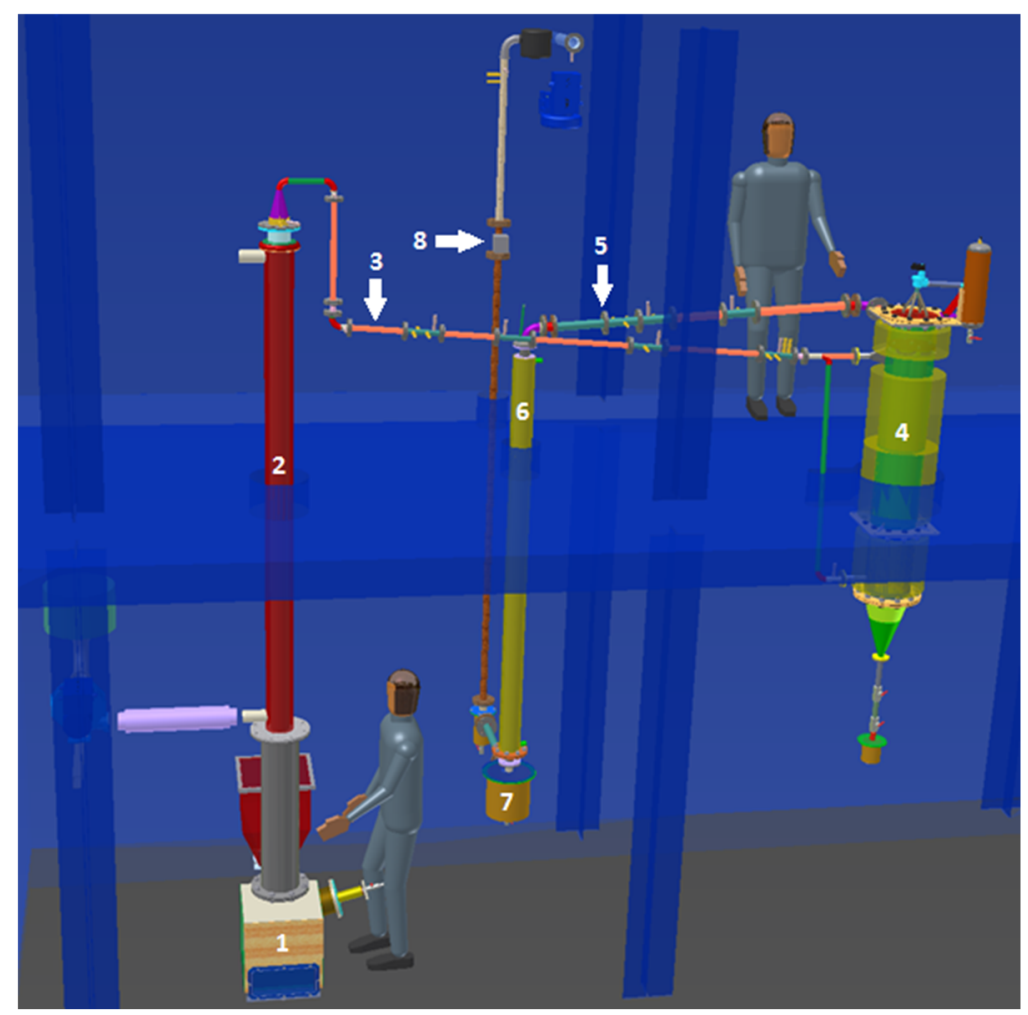

Figure 2: Experimental apparatus, (1) retort burner, (2) co-current air cooler, (3) duct system 1, (4) filter baghouse, (5) duct system 2, (6) countercurrent water cooler, (7) condensation vessel, (8) ultrasonic gas flowmeter.

The apparatus consists of five main parts. The first part is the incineration part, where flue gas is generated. It consists of screw feeder, retort burner, and cocurrent air cooler, where the flue gas temperature is adjusted. The composition of flue gas is to some extent determined by fuel. Change of fuel can, therefore, be an option to modify the flue gas composition.

The second part before the baghouse is the duct system 1, where the flue gas is tempered by a set of electrical heaters. In the duct system 1, the flue gas composition can be modified - solid pollutants (and also sorbents) can be added by slide feeder; gaseous and liquid pollutants (as well as water and reaction agents 
such as ammonia) can be added by means of mass flow meters. This part also allows to conduct samplings and enables the connection of online analysers.

Another part is the cylinder-shaped baghouse, which can comprise up to four one-meter-long filter elements (ceramic or fabric). The flue gas can enter the baghouse by two different ways. The first way of entering the baghouse is tangentially in the upper part. The removal of particulate matter is, in this case, a combination of barrier filtration and cyclonic separation. The second way of entering the baghouse is perpendicularly in the lower part (see Figure 2).

Fourth part is the duct system 2, which is directly behind the baghouse. Its purpose is to allow the collection of samples and flue gas composition measurements.

In the last part, the flue gas is cooled in counter-current water cooler and the condensate is collected in condensation vessels. Subsequently, the flue gas continues through a long straight pipe for the flow to stabilise. Then the stabilised flow of the clean flue gas continues to the ultrasonic gas flowmeter. Subsequently, the flue gas leaves the laboratory.

The apparatus allows testing of filter elements made of Teflon (PTFE, polytetrafluorethylen) or ceramics. The surface of these filter elements can be covered with a catalyst for SCR and oxidation of PCDD/Fs. It also allows testing of the formation of filter cake and cleaning of filter elements. It is possible to generate real flue gas, modify its composition and realise samplings before and after the baghouse. The apparatus allows to conduct samplings and determine the concentration of $\mathrm{SO}_{2}, \mathrm{HCl}, \mathrm{NO}_{\mathrm{x}}, \mathrm{PM}$, heavy metals, $\mathrm{VOC}, \mathrm{TOC}$, and $\mathrm{CO}_{2}$ in flue gas.

\section{Conclusion}

The properties of $\mathrm{NaHCO}_{3}$ are great for sorption of $\mathrm{SO}_{2}$ and $\mathrm{HCl}$ and the sorption process works sufficiently regardless of the process temperature and flue gas humidity. Firstly, $\mathrm{NaHCO}_{3}$ in flue gas decomposes to $\mathrm{Na}_{2} \mathrm{CO}_{3}$, which then reacts with the acidic gases. During the decomposition according to eqn (1), $\mathrm{H}_{2} \mathrm{O}$ and $\mathrm{CO}_{2}$ leave the sorbent and cause the formation of surface structures that help the sorption of acidic gases. Although this surface is smaller than surfaces of some calcium based sorbents, high reactivity of $\mathrm{Na}_{2} \mathrm{CO}_{3}$ formed "in situ" in flue gas enables its use with low stoichiometric excess ratio (1.1-1.4). The disadvantages of $\mathrm{NaHCO}_{3}$ (or generally sodium based sorbents) are relatively low reactivity towards HF, water solubility of air pollution control residues, and its price. Direct use of $\mathrm{Na}_{2} \mathrm{CO}_{3}$ requires activation before use and increases the demands on storage.

$\mathrm{Ca}(\mathrm{OH})_{2}$ is commonly used with higher stoichiometric excess ratio (usually 2.0-2.5). On the other hand, calcium is bivalent. Therefore, in comparison with $\mathrm{NaHCO}_{3}$, only the half of the amount of substance is necessary for removal of the same amount of $\mathrm{SO}_{2}, \mathrm{HCl}$, or $\mathrm{HF}$. The mass of used $\mathrm{NaHCO}_{3}$ and $\mathrm{Ca}(\mathrm{OH})_{2}$ is, for this reason, similar even with the difference of stoichiometric excess ratios. Sorption rate of $\mathrm{HCl}$ on calcium based sorbents is, in comparison with $\mathrm{NaHCO}_{3}$ $\left(\mathrm{Na}_{2} \mathrm{CO}_{3}\right)$, an order of magnitude lower and to reach the emission limits, the flue 
gas treatment has to be conducted under suitable conditions. Suitable temperature for removal of acidic gases by calcium based sorbents is connected to the content of $\mathrm{H}_{2} \mathrm{O}$ in flue gas. The reaction rate is very good in the vicinity of dew point but the process conditions shouldn't be too close to the dew point to avoid condensation. The advantages of calcium based sorbents are better reactivity towards HF, very low water solubility of air pollution residues, and low price in comparison with $\mathrm{NaHCO}_{3}$.

\section{Acknowledgements}

This research was conducted within the Waste to Energy Competence Centre funded by the Technology Agency of the Czech Republic (project TE02000236) and co-financed from specific university research (MSMT No 20-SVV/2016).

\section{References}

[1] Tanaka, H., Comparison of thermal properties and kinetics of decompositions of $\mathrm{NaHCO}_{3}$ and $\mathrm{KHCO}_{3}$. Journal of thermal analysis, 32(2), pp. 521-526, 1987.

[2] Hartman, M., Veselý, V., Svoboda, K., Trnka, O. \& Beran, Z., Dehydration of Sodium Carbonate Decahydrate to Monohydrate in a Fluidized Bed. American Institute of Chemical Engineers, 47(10), pp. 2333-2340, 2001.

[3] Thomé-Kozmiensky, K.J. \& Thiel, S., Waste Management: Volume 5 Waste-to-Energy.: TK Verlag Karl Thomé-Konzmiensky: Neuruppin, pp. 193-220, 2015.

[4] Keener, T.C. \& Davis, W.T., Study of the Reaction of $\mathrm{SO}_{2}$ with $\mathrm{NaHCO}_{3}$ and $\mathrm{Na}_{2} \mathrm{CO}_{3}$. Journal of the Air Pollution Control Association, 34(6), pp. 651654, 1984.

[5] VDI 3460. Emission control-Thermal waste treatment fundamentals. Verein Deutscher Ingenieure e.V.: Düsseldorf, p. 100, 2014.

[6] Choi, J.I., Mun, S.H., Kim, S.T., Hong, M.S. \& Lee J.C., Simultaneous Removal of Particulates and $\mathrm{NO}_{\mathrm{x}}$ Using Catalyst Impregnated Fibrous Ceramic Filters. $5^{\text {th }}$ International Symposium on Gas Cleaning at High Temperatures, SciTech Connect: Morgantown, 2002.

[7] Xhrouet, C., Pipard, C., De Pauw E., De Novo Synthesis of Polychlorinated Dibenzo-p-dioxins and Dibenzofurans on Fly Ash from a Sintering Process. Environmental Science \& Technology, 35(8), pp. 1616-1623, 2001. 